\title{
Nutritional blood parameters and nutritional risk screening in patients with spinal cord injury and deep pressure ulcer-a retrospective chart analysis
}

\author{
Cristina Lussi $^{1} \cdot$ Angela Frotzler $^{1} \cdot$ Andreas Jenny $^{1} \cdot$ Dirk J. Schaefer $^{2} \cdot$ Reto W. Kressig $^{3} \cdot$ Anke Scheel-Sailer $^{1,4}$ \\ Received: 13 April 2017 / Revised: 10 September 2017 / Accepted: 13 September 2017 / Published online: 23 October 2017 \\ (C) International Spinal Cord Society 2018
}

\begin{abstract}
Study design Retrospective chart review.
\end{abstract}

Objectives To describe (i) the nutritional blood parameters (NBP) and the nutritional risk screening (NRS) in patients with spinal cord injury (SCI) and pressure ulcers (PU) III and IV according to the EPUAP classification, and (ii) the relationship between both NBP and NRS.

Setting SCI acute care and rehabilitation clinic in Switzerland.

Methods The NBPs were measured upon the admission of patients treated for PU III and IV between 11/2011 and 12/2014. Descriptive analyses and group comparisons were done.

Results A total of 170 patients, including $42(25 \%)$ women, 19 (12\%) people with paraplegia and 104 (61\%) people with traumatic SCI, were admitted and analyzed. Pathologic blood values and NBP were found for c-reactive protein (83\%), vitamin D (73\%), protein (41\%), erythrocyte sedimentation rate (ESR) $(41 \%)$, albumin (34\%), hemoglobin (34\%), zinc (29\%), folic acid (22\%), transferrin (15.3\%), and copper (1.2\%). Overall, the NRS was $>3$ in $39 \%$ of the patients, wherefrom $28 \%$ in patients with PU III and $44 \%$ with PU IV $(p=0.07)$. No statistical significant differences were found between patients with PU III and IV in terms of NBP and NRS.

Conclusions We found abnormal values in NBP and in NRS in a significant number of patients with SCI and PU of both III and IV. Both laboratory examinations and nutritional assessments at admission can help to detect and correct the nutritional deficits in patients at risk. Neither the grade of the PUs, nor the NBP or the NRS can replace one another.

\section{Introduction}

Pressure ulcers (PU) represent the second most common reason for hospitalization in patients with chronic spinal cord injury (SCI) $[1,2]$. They are classified in accordance

Anke Scheel-Sailer

anke.scheel@paraplegie.ch

Swiss Paraplegic Centre, Nottwil, Switzerland

2 Department of Plastic, Reconstructive, Aesthetic and Hand Surgery, Basel University Hospital, Basel, Switzerland

3 Felix Platter Hospital, University Center for Medicine of Aging, Basel, Switzerland

4 Department of Health Sciences and Health Policy, University of Lucerne, Lucerne, Switzerland with the international consensus conferences [3] in four severity levels ( $\mathrm{I}=$ intact skin with non-blanchable redness, $\mathrm{II}=$ partial thickness loss of the dermis presenting as a shallow open ulcer, III=full thickness tissue loss, IV=full thickness tissue loss with exposed bone, tendon or muscle) [3]. More than 200 causal risk factors for PUs have been described in the existing literature. They can be divided into external factors such as pressure, friction, shearing forces, and moisture, and internal factors such as infection, hypotension, malnutrition, anemia, and autonomic dysregulation [3, 4]. Complex interdisciplinary treatment plans address these risk factors $[1,5,6]$, although the exact causality in these is still not clear. In addition, the discussion on diagnoses of malnutrition with the need for blood examination and nutrition screening instruments remains challenging [3]. 
There is evidence that malnutrition affects the development and healing of PU in SCI patients [1,3]. Patients with SCI suffer from an increased risk of malnutrition due to physiological changes such as an increased energy demand, protein catabolism and nitrogen excretion, and reduced intestinal absorption by the autonomic dysfunction [7]. The prevalence of malnutrition recorded by the Spinal Nutrition Screening Tool (SNST) in hospitalized patients with SCI was reported to be $45 \%$ and the length of hospital stay and morbidity were significantly higher in the group of malnourished patients. In this study, the serum albumin could even be used as a predictor for a longer hospitalization [8]. The relation between albumin, malnutrition, and morbidity risk is increasingly discussed also in the general acute care, but not finally clarified [9-12].

Looking into the general hospital population in a multicentre study, a positive correlation between malnutrition and the incidence of PU was shown (OR 10.46, $p<0.05$ ) [13]. The patients suffering from PU (III-IV) showed an increased basal metabolic rate and calorie requirement of $23.7 \mathrm{kcal} / \mathrm{kg} /$ day compared with the patients without PU who had a calorie requirement of $20.7 \mathrm{kcal} / \mathrm{kg} / \mathrm{day}$ [14]. The awareness of malnutrition as a risk factor during general hospitalization has initiated systematic, simple, and quickly performed assessments such as the Mini Nutrition Assessment. But its validity and specificity to detect patient at risk of malnutrition are still under discussion [15, 16]. Deep PUs are judged as moderate hypermetabolism and directly lead to a two-point risk on a seven-point scale in the NRS. Weight loss, decreased appetite, age over 70 years, and low BMI $(<20.5)$ additionally elevates the risk of malnutrition. The recommendations are based on the total sum score, with no intervention recommended for a score of zero, low scores up to two points suggesting observation and an eating protocol and for higher risk scores, there are recommendations for individualized nutritional support [17]. In a first study, in seriously ill patients, who were classified as malnourished based on the Nutritional Risk Screening (NRS) and accordingly, additionally nourished, a better outcome including the length of stay and mortality was shown ( $p=0.0006$, OR 1.7) [17]. For a differentiated assessment of malnutrition and in addition to the Screening Tool or Assessment, there is usually a laboratory analysis of proteins (albumin, transferrin, pre-albumin), lymphocyte count, hemoglobin/iron status, zinc, folate, and Vitamin B12 [18]. Because of lack of evidence, it is unclear both in the geriatric population, as well as specifically in the patients with SCI, which trace elements should be systematically tested and supplemented when treating PU $[19,20]$.

Therefore, the aim of this study is to describe NBP and NRS in patients with SCI and deep PU (III and IV) and to analyze the relation of both NBP and NRS. These results will help decide whether one of the two can substitute the other and can in addition support the development of therapeutic nutrition concepts in patients with SCI and PU.

\section{Methods}

\section{Study population}

Men and women admitted for in-patient treatment of deep PU (III or IV according to the European Pressure Ulcer Advisory Panel [3]) between November 2011 and December 2014 were included and treated according to the Basler Decubitus concept [5]. All the patients were at least 18 years old and had an SCI classified by the American Spinal Injury Association Impairment Scale (AIS) A-D. Our non-traumatic group also included patients with spina bifida. One patient who did not consent to the retrospective data analyses was excluded. The Ethics Commission Northwest and Central Switzerland approved this study (EKNZ 2014-107) and all regulations concerning retrospective data analyses were respected.

\section{Setting}

The specialized acute care and rehabilitation clinic for SCI offers comprehensive treatment for PU at all stages. According to the Basler Decubitus concept [5, 6], patients with SCI and PU III and IV are treated in a comprehensive, interdisciplinary concept involving a specialist for the paraplegia (rehab and general medicine), a plastic surgeon, rehab nurses, wound care specialist, physio- and occupational therapists, dieticians, and a psychotherapist $[6,21]$.

\section{Nutrition variables}

By the end of 2011, a combined standard as part of the Basler Decubitus concept has been established in our institution, including nutritional screenings, dietician consultations, standard blood parameters-hemoglobin, creatinine, potassium, sodium, c-reactive protein (CRP), erythrocyte sedimentation rate (ESR), ferritin, albumin, protein, iron, transferrin-and a predefined nutritional profile in every patient with a deep PU (vitamin B1, vitamin D, vitamin B12, zinc, selenium, folic acid, copper). This approach was the result of a consensus process between a rehab physician, a laboratory specialist, and the dietician, based on the existing evidence.

\section{Data collection}

The data were extracted retrospectively from digital medical records (clinical information systems Nexus 2.2 and Ixserv.4). The patient characteristics such as gender, age at admission, the AIS score, the level of injury, time since onset of the lesion, etiology of injury, PU localization, 
Table 1 Characteristics of patients with spinal cord injury $(N=170)$ with PU III and IV, total and subgroups

\begin{tabular}{|c|c|c|c|c|}
\hline & $\begin{array}{l}\text { In total } n \\
(\%)\end{array}$ & $\begin{array}{l}\text { PU III } \\
n(\%)\end{array}$ & $\begin{array}{l}\text { PU IV } \\
n(\%)\end{array}$ & $\begin{array}{l}\text { Test } \\
p \text {-value* }\end{array}$ \\
\hline Sex & & & & 0.257 \\
\hline Male & $128(75)$ & $35(76)$ & $93(75)$ & \\
\hline Female & $42(25)$ & $11(24)$ & $31(25)$ & \\
\hline \multicolumn{5}{|l|}{ Etiology of SCI } \\
\hline Traumatic SCI & & & & 0.175 \\
\hline Transport activity & $42(25)$ & $16(35)$ & $26(21)$ & \\
\hline $\begin{array}{l}\text { Sports and leisure } \\
\text { activity }\end{array}$ & $12(7)$ & $4(9)$ & $8(7)$ & \\
\hline Fall & 33 (19) & $9(20)$ & $24(19)$ & \\
\hline $\begin{array}{l}\text { After surgical } \\
\text { intervention }\end{array}$ & $4(2)$ & 0 & $4(3)$ & \\
\hline Other accident cause & $13(8)$ & $2(4)$ & $11(9)$ & \\
\hline \multicolumn{5}{|l|}{ Non traumatic SCI } \\
\hline Multiple Scleroses & $13(8)$ & $2(4)$ & $11(9)$ & \\
\hline Tumor & $5(3)$ & $2(4)$ & $3(2)$ & \\
\hline Infection & $2(1)$ & 0 & $2(2)$ & \\
\hline Inflammation & $1(1)$ & $1(2)$ & 0 & \\
\hline Bleeding & $1(1)$ & $1(2)$ & 0 & \\
\hline Other disease & $31(18)$ & $8(17)$ & $23(19)$ & \\
\hline Undefined & $13(8)$ & $1(2)$ & $12(10)$ & \\
\hline Neurological level of SCI & & & & 0.843 \\
\hline $\mathrm{C} 1-\mathrm{C} 4 \mathrm{~A}, \mathrm{~B}, \mathrm{C}$ & $110(65)$ & $28(61)$ & $82(66)$ & \\
\hline $\mathrm{C} 5-\mathrm{C} 8 \mathrm{~A}, \mathrm{~B}, \mathrm{C}$ & $24(14)$ & $9(20)$ & $15(12)$ & \\
\hline T1-sS5 A,B,C & $18(11)$ & $5(11)$ & $13(11)$ & \\
\hline All AIS D & $1(1)$ & 0 & $1(1)$ & \\
\hline Pressure Ulcer Location & & & & $0.001 *$ \\
\hline Foot & $24(14)$ & $8(17)$ & $16(13)$ & \\
\hline Genitals & $2(1)$ & $1(2)$ & $1(1)$ & \\
\hline Buttocks & $6(4)$ & $3(7)$ & $3(2)$ & \\
\hline Head & $1(1)$ & $1(2)$ & $0(0)$ & \\
\hline Upper extremities & $4(2)$ & $2(4)$ & $2(2)$ & \\
\hline Torso & $3(2)$ & $2(4)$ & $1(1)$ & \\
\hline Ischium & $85(50)$ & $15(32)$ & $70(57)$ & \\
\hline Coccyx/Sacrum & $38(22)$ & $8(17)$ & $30(24)$ & \\
\hline Lower extremities & $5(3)$ & $5(11)$ & $0(0)$ & \\
\hline Inguinal & $2(1)$ & $1(2)$ & $1(1)$ & \\
\hline Number of PU & & & & 0.602 \\
\hline 1 & $115(68)$ & $27(59)$ & $88(71)$ & \\
\hline 2 & $32(19)$ & $11(24)$ & $21(17)$ & \\
\hline$\geq 3$ & $23(14)$ & $8(17)$ & $15(12)$ & \\
\hline $\begin{array}{l}\text { Domicile before } \\
\text { admission }\end{array}$ & & & & 0.511 \\
\hline Home & $90(53)$ & $28(61)$ & $62(50)$ & \\
\hline Home with SPITEX care & $51(30)$ & $14(30)$ & $37(30)$ & \\
\hline Nursing home & $1(1)$ & $0(0)$ & $1(1)$ & \\
\hline Hospital & $17(10)$ & $2(4)$ & 15 (12) & \\
\hline
\end{tabular}

Table 1 continued

\begin{tabular}{|c|c|c|c|c|}
\hline & $\begin{array}{l}\text { In total } n \\
(\%)\end{array}$ & $\begin{array}{l}\text { PU III } \\
n(\%)\end{array}$ & $\begin{array}{l}\text { PU IV } \\
n(\%)\end{array}$ & $\begin{array}{l}\text { Test } \\
p \text {-value* }\end{array}$ \\
\hline Assisted living residence & $8(5)$ & $2(4)$ & $6(5)$ & \\
\hline Group living situation & $3(2)$ & $0(0)$ & $3(2)$ & \\
\hline $\begin{array}{l}\text { Social Status at the time } \\
\text { of entry }\end{array}$ & & & & 0.061 \\
\hline Single & $59(35)$ & $24(52)$ & $35(28)$ & \\
\hline Married & $54(32)$ & $12(26)$ & $42(34)$ & \\
\hline Widowed & $11(7)$ & $1(2)$ & $10(8)$ & \\
\hline Divorced & $15(9)$ & $2(4)$ & $13(11)$ & \\
\hline Partnership & 29 (17) & $6(13)$ & $23(19)$ & \\
\hline Other & $2(1)$ & $1(2)$ & $1(8)$ & \\
\hline $\begin{array}{l}\text { Age at Injury (year): } \\
\text { median (IQR) }\end{array}$ & $32(21)$ & $41(34)$ & $30(20)$ & 0.801 \\
\hline $\begin{array}{l}\text { Years since Injury: } \\
\text { median (IQR) }\end{array}$ & $21(24)$ & $12(22)$ & $23(21)$ & 0.005 \\
\hline $\begin{array}{l}\text { Age at Admission (year): } \\
\text { median (IQR) }\end{array}$ & $54(21)$ & $49(22)$ & $55(23)$ & 0.007 \\
\hline $\begin{array}{l}\text { Length of Stay (day): } \\
\text { median (IQR) }\end{array}$ & $85(47)$ & $74(48)$ & $87(40)$ & 0.014 \\
\hline $\begin{array}{l}\text { Data were not norma } \\
\text { Shapiro-Wilk test) }\end{array}$ & y dis & ed & $\operatorname{mog}$ & v-Smirnov, \\
\hline \multicolumn{5}{|c|}{$\begin{array}{l}S C I \text { spinal cord injury, } P U \text { pressure ulcer, } A I S \text { American Spinal Injury } \\
\text { Association Impairment Scale, } I Q R \text { interquartile range }\end{array}$} \\
\hline
\end{tabular}

social status, and residence were grouped according to the recommendation of International Spinal Cord Society [22] and the SwiSCI Cohort study protocol [23]. In the nontraumatic group, spina bifida was coded as other diseases. The nutrition-specific information (involuntary loss of weight, vitamin substitution, loss of appetite, $\mathrm{BMI}<18$, and metabolic stress) was documented according to the NRS [17]. Because of missing information about the ability to eat and comorbidities, we decided not to reconstruct the SNST. In the case of missing NRS-relevant information like the loss of weight or appetite, the NRS score was calculated based only on the existing data. Blood analyses were interpreted according to the published reference ranges describing $95 \%$ percent of a normal population sample. In addition to creatinine, serum cystatine $\mathrm{C}$ was used to estimate the glomerular filtration rate [24]. The blood values were collected, divided in interval scales, and finally, transformed into dichotomous scales using the standard cutoff values (normal and pathological values).

\section{Analysis}

Descriptive statistics were expressed as frequencies and percentage for discrete variables (gender, pathologic values) 
and were expressed as medians (interquartile range (IQR)) for the continuous variables if not normally distributed (e.g., age at lesion, time since lesion) and as means (standard deviation, SD) if normally distributed (e.g., labor values). The normal distribution was tested with the KolmogorovSmirnov test.

Group comparisons were done for PU III vs. PU IV for categorical variables with Chi-square respective Fisher Exact Test. For normally distributed data, we performed ANCOVA with nutrition parameters as dependent variables and age at admission as well as years since injury as covariates. Further subgroup analyses with respect to NRS Groups $1-2$ vs 3-7 and pathologic vs normal NBP for PU III and PU IV were done. The NRS was calculated as required [17]. Two clinical experts checked all the results for plausibility. The relation between CRP and albumin was calculated in the subgroup PU III vs. PU IV and correlation and cross tables were done. The Bonferroni correction was applied in order to correct for multiple testing.

The significance level was set at $\alpha=0.05$. All analyses were performed with SPSS version 21 (IBM Corp., Armonk, NY).

\section{Results}

The patient characteristics are shown in Table 1. Of all the patients, $128(75 \%)$ were men, $19(12 \%)$ had a paraplegia, 104 patients $(61 \%)$ had a traumatic SCI, and 14 patients were diagnosed with spina bifida. The PUs were most often localized in the sitting region (129 patients, 76\%), no PU occurred at the trochanter or at the chest, and 115 had only one PU (68\%). The median length of stay was 85 days (IQR 47). A total of 141 patients were living at home, of whom 51 had professional nursing services. In total 85 patients lived alone, of whom 11 were widowed (Table 1).

We found a high percentage of pathological blood parameters in all patients with SCI for CRP (83\%) and vitamin D (73\%) and moderate percentage of pathological blood parameters for protein (41\%), ESR (41\%), albumin (34\%), hemoglobin (34\%), zinc (29\%), sodium (24\%), folic acid $(22 \%)$, transferrin (15\%) (Table 2). Vitamin D deficiency $(\leq 50 \mathrm{nmol} / \mathrm{l})$ was found in 83 and relative deficiency $(\leq 75 \mathrm{nmol} / \mathrm{l})$ in 40 patients. Creatinine was pathologically elevated in $4 \%$ and cystatin-C-based calculations indicated in $17(10 \%)$ of all patients with SCI a glomerular filtration rate below $30 \mathrm{ml} / \mathrm{min}$ and in $22(13 \%)$ patients $30-60 \mathrm{ml} /$ min. The distribution of albumin (pathologic vs. normal) in relation to CRP groups is shown in Table 3. A weak but significant correlation was found between CRP and albumin $\left(r=-270^{* *}, p<0.000\right)$, indicating a reduced albumin in patients with elevated CRP.
In total $39 \%$ of all patients showed a high-risk NRS (NRS 3-7) (Table 4). Group differences in frequencies between malnutrition according to the NRS and patients with PU III or IV were not significant ( $p=0.107$ for single NRS values, $p=0.07$ for NRS groups). We found no statistical different percentages of pathological NBP in all patients with SCI and PU III or IV (Table 5). Vitamin D and protein correlated significantly with age at admission ( $p<0.000$, respectively $p=0.001)$. Living at home with nursing care support in $57 \%$ and being married in $52 \%$, was associated with NRS 2 in $64 \%$. We found a high percentage of NSR $3(73 \%)$ in the widowed patients. The NRS on average did not differ significantly for types of residence.

\section{Discussion}

We found abnormal values in the NBP both in laboratory examinations and in nutritional risk assessment tools in a significant number of patients with SCI and PU. The most pathological laboratory values were, in decreasing order, CRP, vitamin D, protein, ESR, albumin, hemoglobin, zinc, sodium, folic acid, and transferrin. Statistically significant differences between NBP with respect to NRS groups (NIR1-2 vs. NRS 3-7) were found in albumin, protein, Vitamin D, and C-reactive protein $(p<0.05)$.

\section{Laboratory parameters}

Looking at the mostly increased infection parameter as CRP, ESR, and ferritin, the acute inflammatory part of the disease PU in SCI becomes obvious [25, 26]. The inflammatory state influences the other laboratory parameters, especially in the judgment of the nutritional status [12]. The decreased albumin values in our population, as well as in others [19] might be an expression of malnutrition and/or metabolic stress according to the inflammatory status $[8$, 10-12]. We found a significant, low negative but weak correlation between CRP and albumin and therefore, both CRP and albumin add information in individual patients and help to understand their malnutrition and infection status. The relation between CRP and changes in albumin are increasingly discussed because the combined factor indicates an increased mortality and can be used as a predictor in acute care $[10,11]$. Ferritin, an acute phase protein and iron carrier [12], is used as well, as an indicator for iron deficiency in situations with normal CRP. We also found reduced hemoglobin in 33\% and reduced transferrin in $95 \%$ of our population compared to others $[25,26]$ and due to the direct and strong positive correlation between ferritin und $\mathrm{CRP}$, in cases of anemia, a deeper diagnostics of every patient with ferritin $<100 \mu \mathrm{g} / \mathrm{l}$ is recommended. So, for the differentiation of acute infection vs. malnutrition, a follow- 
Table 2 Description and comparison of the nutrition blood parameters in patients with SCI and third-degree PU $(N=46)$ and fourth-degree PU $(N=124)$

\begin{tabular}{|c|c|c|c|c|c|c|c|c|c|c|c|}
\hline \multirow{2}{*}{$\begin{array}{l}\text { Nutrition } \\
\text { parameter }\end{array}$} & \multirow{2}{*}{$\begin{array}{l}\text { Reference } \\
\text { values } \\
\text { Normal } \\
\text { population }\end{array}$} & \multicolumn{3}{|c|}{ All patients } & \multicolumn{3}{|c|}{ Patients with PU III } & \multicolumn{3}{|c|}{ Patients with PU IV } & \multirow[t]{2}{*}{$p$-value* } \\
\hline & & $\bar{N}$ & mean \pm SD & $\begin{array}{l}\% \\
\text { pathologic }\end{array}$ & $\bar{N}$ & mean \pm SD & $\%$ pathologic & $\bar{N}$ & mean \pm SD & $\%$ pathologic & \\
\hline Albumin & $35-50 \mathrm{~g} / 1$ & 169 & $37 \pm 7$ & 34 & 46 & $37 \pm 4$ & 26 & 123 & $36 \pm 7$ & 36 & 0.703 \\
\hline Protein & $64-83 \mathrm{~g} / 1$ & 169 & $64 \pm 7$ & 41 & 46 & $65 \pm 6$ & 41 & 123 & $64 \pm 7$ & 41 & 0.902 \\
\hline Hemoglobin & $140-170 \mathrm{~g} / 1$ & 170 & $126 \pm 21$ & 34 & 46 & $131 \pm 18$ & 22 & 124 & $124 \pm 22$ & 38 & 0.374 \\
\hline Vitamin B12 & $139-652 \mathrm{pmol} / \mathrm{l}$ & 169 & $287 \pm 169$ & 7 & 46 & $278 \pm 156$ & 2 & 123 & $291 \pm 174$ & 8 & 0.556 \\
\hline Vitamin B1 & $66-200 \mathrm{nmol} / 1$ & 164 & $146 \pm 49$ & 0 & 45 & $145 \pm 42$ & 0 & 119 & $147 \pm 51$ & 0 & 0.462 \\
\hline Folic acid & $7.2-41 \mathrm{nmol} / 1$ & 169 & $15.7 \pm 11.2$ & 22 & 46 & $13.2 \pm 8.6$ & 22 & 123 & $16.5 \pm 11.9$ & 23 & 0.296 \\
\hline Zinc & $9-22 \mathrm{mcm} / \mathrm{l}$ & 170 & $10 \pm 2.3$ & 29 & 46 & $10 \pm 2$ & 17 & 124 & $10 \pm 2$ & 33 & 0.928 \\
\hline Copper & $12-24 \mathrm{nmol} / \mathrm{l}$ & 168 & $21 \pm 4.3$ & 1 & 46 & $21 \pm 3$ & 0 & 122 & $21 \pm 4$ & 2 & 0.995 \\
\hline Selenium & $0.5-1.5 \mathrm{mcmol} / \mathrm{l}$ & 167 & $0.9 \pm 0.3$ & 10 & 45 & $0.9 \pm 0.2$ & 9 & 122 & $0.8 \pm 0.2$ & 11 & 0.238 \\
\hline $\begin{array}{l}\text { 25-OH Vitamin } \\
\text { D }\end{array}$ & $75-220 \mathrm{nmol} / \mathrm{l}$ & 166 & $57 \pm 34$ & 73 & 45 & $55 \pm 33$ & 78 & 121 & $58 \pm 34$ & 74 & 0.818 \\
\hline CRP & $<5 \mathrm{mg} / \mathrm{l}$ & 170 & $46 \pm 59$ & 83 & 46 & $33 \pm 38$ & 78 & 124 & $50 \pm 65$ & 85 & 0.155 \\
\hline Creatinine & $59-104 \mu \mathrm{mol} / 1$ & 169 & $54 \pm 38$ & 4 & 46 & $57 \pm 23$ & 7 & 123 & $53 \pm 42$ & 3 & 0.539 \\
\hline Sodium & $135-145 \mathrm{mmol} / \mathrm{l}$ & 170 & $136 \pm 4$ & 24 & 46 & $137 \pm 4$ & 20 & 124 & $136 \pm 4$ & 26 & 0.723 \\
\hline Potassium & $3.5-5.1 \mathrm{mmol} / \mathrm{l}$ & 170 & $4.2 \pm 0.4$ & 7 & 46 & $4.2 \pm 0.4$ & 7 & 124 & $4.2 \pm 0.4$ & 7 & 0.95 \\
\hline Ferritin & $15-150 \mu \mathrm{g} / 1$ & 167 & $246 \pm 316$ & 4 & 46 & $236 \pm 323$ & 7 & 121 & $250 \pm 314$ & 3 & 0.646 \\
\hline Iron & $8.8-27 \mu \mathrm{mol} / \mathrm{l}$ & 29 & $6.7 \pm 3.4$ & 12 & 9 & $6.7 \pm 2.8$ & 15 & 20 & $6.8 \pm 3.8$ & 11 & 0.923 \\
\hline Transferrin & $220-370 \mathrm{mg} / \mathrm{dl}$ & 27 & $10 \pm 42$ & 15 & 8 & $2.2 \pm 0.8$ & 100 & 19 & $14 \pm 51$ & 95 & 0.585 \\
\hline ESR & $<20 \mathrm{~mm} / \mathrm{h}$ & 82 & $54 \pm 29$ & 41 & 30 & $46 \pm 31.3$ & 48 & 52 & $59.4 \pm 28.4$ & 39 & 0.015 \\
\hline
\end{tabular}

Data were normally distributed according to Kolmogorov-Smirnov tests

$S C I$ spinal cord injury, $N$ number, $S D$ standard deviation, $P U$ pressure ulcer, $C R P$ c reactive protein, $E S R$ erythrocyte sedimentation rate

*Significance level after Bonferroni correction is $\alpha=0.0028$

*ANCOVA for group comparison in patients with SCI and third- and fourth-degree PU with nutrition parameters as the dependent variables and age at admission, as well as years since injury as the covariates

up examination of albumin and ferritin is especially needed in cases of reduced hemoglobin, when CRP is normalized.

We found reduced Vitamin D in $73 \%$ of our population with SCI and PU as the second most frequent pathological parameter. This implicates a strong correlation between vitamin D deficiency and PU in patients with SCI [20], which suggests the recommendation of regularly testing and supplementation of vitamin D in case of deficiency. Comparing our results to the existing literature, same or comparable deficiency percentages of vitamin D were recently found in other populations with SCI without the presence of PU [27, 28]. These populations include chronic SCI [28], elite wheelchair athletes [27], acute and chronic SCI, and African Americans, but the epidemiological examination of the general populations with SCI are still missing [27]. Beside the known prevalence in the patients with SCI [20], the real causality between vitamin D deficiency and PU development in SCI people remains unclear. Therefore, with the current knowledge, we recommend the regular testing of vitamin D in patients with SCI and PU, followed by the supplementation of vitamin D deficiencies to optimize wound healing [29] and to increase muscle strength [30].

We found zinc deficiency in $28 \%$ of our SCI population similar to the earlier studies [19]. Taking into consideration the newly upcoming evidence [31, 32], zinc-substitution in combination with enriched nutrition leads to better healing of PUs. Therefore, we recommend regular testing und supplementation if necessary. Sodium was reduced in $24 \%$ of our population compared to the general SCI population admitted to a hospital [33] and sodium levels should be regularly tested and treated. Selenium deficiency was found in $10 \%$ and because it is supplemented without any side effects to optimize wound healing [34], no regular screening seems necessary. Although vitamin B12 was only pathological in $7 \%$, we recommended the screening for deficiency because of the clinical relevance of vitamin B12. Folic acid usually normalizes within some days of balanced nutrition and we see no need for regular examination, although we found pathological values in $22 \%$ of our patients. We do not recommend the regular screening of 
Table 3 Distribution of albumin (pathologic versus normal) in relation to the CRP groups in patients with SCI and PU $(N=169)$

CRP Groups

\begin{tabular}{lllllll}
\hline & CRP $<5$ & CRP 5-10 & CRP 11-40 & CRP 41-100 & CRP $>100$ & Total \\
\hline Normal Albumin & 3 & 4 & 18 & 21 & 11 & 57 \\
Pathologic Albumin & 25 & 22 & 33 & 24 & 8 & 112 \\
Total & 28 & 26 & 51 & 45 & 19 & 169 \\
\hline
\end{tabular}

Table 4 Description of nutritional risk screening (NRS) in patients with SCI and PU III and IV

\begin{tabular}{lllll}
\hline & $\begin{array}{l}\text { All Patients } n \\
(\%)\end{array}$ & $\begin{array}{l}\text { PU III } n \\
(\%)\end{array}$ & $\begin{array}{l}\text { PU IV } \\
n(\%)\end{array}$ & $\begin{array}{l}\text { Test } \\
p \text {-value* }\end{array}$ \\
\hline Vitamin substitution & $53(31.2)$ & $17(37)$ & $36(29)$ & \\
Loss of appetite & $11(7)$ & $2(4)$ & $9(7)$ & \\
Involuntary loss of & $17(10)$ & $3(7)$ & $14(11)$ & \\
weight & & & & \\
BMI < 18 & $31(18)$ & $10(22)$ & $21(17)$ & \\
NRS 1 & 0 & 0 & 0 & 0.107 \\
NRS 2 & $103(61)$ & $33(72)$ & $70(57)$ & \\
NRS 3 & $33(20)$ & $3(7)$ & $30(24)$ & \\
NRS 4 & $19(11)$ & $5(11)$ & $14(11)$ & \\
NRS 5 & $14(8)$ & $5(11)$ & $9(7)$ & \\
NRS 6 & $1(1)$ & $0(0)$ & $1(1)$ & \\
NRS 1-2 & $103(61)$ & $33(72)$ & $70(57)$ & 0.070 \\
NRS 3-7 & $67(39)$ & $13(28)$ & $54(44)$ & \\
\hline
\end{tabular}

$B M I$ body mass index, $S C I$ spinal cord injury, $P U$ pressure ulcer

* Group comparison of patients with PU III and PU IV NRS overall, and NRS dichotom (NRS 1-2 and NRS 3-7); Chi-square test respective Fisher Exact Test. *Significance level after Bonferroni correction is $\alpha=0.0028$

vitamin B1 and copper because in our population it was only pathologic in $0.0 \%$ and $1 \%$, respectively.

\section{Nutritional Risk Screening and relationship to blood parameters}

In addition to the examination of blood parameters, the NRS was collected and analyzed to cover the relevant complementary aspects such as the loss of weight, body mass index, and appetite [17]. The implementation of the nutritional assessments in hospital patients (e.g., geriatric patients) is strongly recommended because of its relevant prognostic parameters for malnutrition [16]. The NRS was 3-7 in 39\% of our patient population and correlated to pathologic protein, albumin, CRP, and vitamin D. The reason behind comparing the blood parameters with NRS was to find possible correlations with a view to substitute one with the other or to influence the therapeutic nutritional concepts. In the present discussion, the complexity of
Table 5 Description of nutritional risk screening (NRS) frequencies and percentages of pathologic blood parameters in patients with SCI and PU III or IV

\begin{tabular}{|c|c|c|c|}
\hline & $\begin{array}{l}\text { NRS 1-2 } \\
n(\%)\end{array}$ & $\begin{array}{l}\text { NRS 3-7 } \\
n(\%)\end{array}$ & $p$-value* \\
\hline Albumin & $27(26)$ & $30(46)$ & 0.010 \\
\hline Protein & $35(34)$ & $35(53)$ & 0.014 \\
\hline Hemoglobin & $29(28)$ & $28(42)$ & 0.066 \\
\hline Vitamin B12 & $7(7)$ & $4(6)$ & 0.453 \\
\hline Vitamin B1 & $0(0)$ & $0(0)$ & NA \\
\hline Folic acid & $22(21)$ & $16(24)$ & 0.419 \\
\hline Zinc & $25(24)$ & $24(36)$ & 0.104 \\
\hline Copper & $1(1)$ & $1(2)$ & 0.755 \\
\hline Selenium & $8(8)$ & $9(14)$ & 0.232 \\
\hline 25-OH Vitamin D & $81(81)$ & $43(65)$ & 0.022 \\
\hline CRP & $91(88)$ & $50(75)$ & 0.020 \\
\hline Sodium & $27(26)$ & $14(21)$ & 0.428 \\
\hline Potassium & $6(6)$ & $5(8)$ & 0.672 \\
\hline Ferritin & $3(3)$ & $4(6)$ & 0.330 \\
\hline Iron & $5(31)$ & $3(23)$ & 0.624 \\
\hline Transferrin & $15(94)$ & $11(100)$ & 0.398 \\
\hline ESR & $43(90)$ & $27(79)$ & 0.199 \\
\hline Creatinine & $5(5)$ & $2(3)$ & 0.549 \\
\hline GFR & $1(14)$ & $1(20)$ & 0.670 \\
\hline
\end{tabular}

$B M I$ body mass index, $P U$ pressure ulcer

*Significant differences in Chi-Square Test. after Bonferroni correction is $\alpha=0.0028$

nutritional status diagnosis is evident and neither the grade of the PUs, nor the NBP or the NRS can replace one another. The lack of significant differences in the percentages of NRS $>3$ in patients with PU III vs. PU IV does not allow for taking the grades of PU as an indicator for malnutrition and the partial correlation between high NRS. Also the pathological blood parameters don't allow the substitution of one examination with the other to identify malnutrition. To summarize, we suggest initiating nutritional counseling in all patients with SCI and deep PUs due to the high percentages of pathological blood parameters and pathological NRS with respect to the higher mortality rates in malnourished patients with SCI [8]. 
The discussion about NRS in the population with SCI leads to the selection of a suitable nutritional assessment tool in accordance with the specific patient group characteristics. Actually, several different nutritional assessment tools such as NRS, MUST, and MNA-SF have been developed and scientifically compared. With a view for nationwide comparison of nutrition, a standard assessment should be developed and recommended, but for clinical usability, the selection of specific nutritional screenings is the best. The SNST is the most useful assessment in the SCI patients to identify the patients at risk of malnutrition, including SCI specific characteristics [35].

\section{Clinical relevance}

Laboratory examinations and assessments at admission can help to detect and correct nutritional deficits in patients at risk in order to optimize wound healing. Primarily, the knowledge of the relevant nutritional blood parameters for the patients with SCI and PU is required to develop the recommendations for diagnosis and therapy of the malnourished patients with SCI and PU. At the same time, based on these data, a generally executed nutritional assessment such as the SNST is recommended to add the relevant clinical aspects of malnutrition and to provide data for nation-specific comparisons. Due to the complex situation and the special nutritional needs during the treatment phase of PU in the SCI patients, additional nutritional counseling is recommended. The effect of these integrated treatment concepts on wound healing should be examined in prospective observational studies.

\section{Strength and weaknesses}

No comparison groups, such as patients with SCI and PU stage 1 and 2 or healthy SCI persons were available and therefore, the correlation for PU development and malnutrition has to be interpreted with caution. The NRS was not part of the clinical routine and had to be created retrospectively out of the patient data records. In 22 patients, information about appetite or BMI was missing; higher NRS scores might be attained with higher data quality. The SNST, as a currently recommended nutritional assessment tool for patients with SCI, was not available in our population and observation period. Some of the laboratory examinations (e.g., iron and transferrin) were only examined in a small subpopulation and therefore, the generalizability of this study is reduced.

\section{Conclusions}

Laboratory examinations and nutritional assessments at admission can help to detect and correct nutritional deficits in patients at risk in order to optimize wound healing. Laboratory results have to be interpreted with caution and respect all influencing factors. Due to the increased nutritional needs and changed metabolism, nutritional counseling and a complex and interdisciplinary treatment approach are required.

\section{Data archiving}

All relevant data are within this manuscript and raw data are archived by the authors.

Acknowledgements We would like to thank all the professionals at the SPZ for contributing to the data collection and in particular we thank Yvonne Häberli. We would like to thank Stefani Tesini for her support in the statistical analyses and Erna und Perry Reed for correcting the English language.

\section{Compliance with ethical standards}

Conflict of interest The authors declare that they have no competing interests.

\section{References}

1. SCIRE. Spinal Cord Rehabilitation Evidence. Vancouver, BC: SCIRE Project/ Monkey Hill Health Communications, 2016. https://scireproject.com/.

2. DeVivo M, Farris V. Causes and costs of unplanned hospitalizations among persons with spinal cord injury. Top Spinal Cord Inj Rehabil. 2011;16:53-61.

3. NPUAP/EPUAP. Prevention and Treatment of Pressure Ulcers: Quick Reference Guide, 2014. https://www.npuap.org/wpcontent/uploads/2014/08/Updated-10-16-14-Quick-ReferenceGuide-DIGITAL-NPUAP-EPUAP-PPPIA-16Oct2014.pdf.

4. Bansal C, Scott R, Stewart D, Cockerell CJ. Decubitus ulcers: a review of the literature. Int J Dermatol. 2005;44:805-10.

5. Wettstein R, Tremp M, Baumberger M, Schaefer DJ, Kalbermatten DF. Local flap therapy for the treatment of pressure sore wounds. Int Wound J. 2015;572-76.

6. Rieger U, Scheufler O, Schmid D, Zweifel-Schlatter M, Kalbermatten D, Pierer G. Six treatment principles of the basle pressure sore concept. Handchirurgie Mikrochirurgie Plastische Chirurgie. 2007;39:206-14.

7. Dionyssiotis Y. Malnutrition in spinal cord injury: more than nutritional deficiency. J Clin Med Res. 2012;4:227.

8. Wong S, Derry F, Jamous A, Hirani SP, Forbes A. Is undernutrition risk associated with an adverse clinical outcome in spinal cord-injured patients admitted to a spinal centre? Eur J Clin Nutr. 2014;68:125-30.

9. Academy of Nutrition and Dietetics. Spinal Cord Injury EvidenceBased Nutrition Practice Guideline, 2014. https://www.andeal. org/topic.cfm?cat=3485.

10. Hübner $\mathrm{M}$, Mantziari $\mathrm{S}$, Demartines $\mathrm{N}$, Pralong $\mathrm{F}$, Coti-Bertrand P, Schäfer M. Postoperative albumin drop is a marker for surgical stress and a predictor for clinical outcome: a pilot study. Gastroenterol Res Pract. 2016. http://dx.doi.org/10. 1155/2016/8743187.

11. Kim MH, Ahn JY, Song JE, Choi H, Ann HW, Kim JK, et al. The $\mathrm{C}$-reactive protein/albumin ratio as an independent predictor of mortality in patients with severe sepsis or septic shock treated with early goal-directed therapy. PLoS ONE. 2015;10:e0132109. 
12. Thurnham DI, Northrop-Clewes CA. Inflammation and biomarkers of micronutrient status. Curr Opin Clin Nutr Metab Care. 2016;19:458-62.

13. Brito PA, Generoso Sde V, Correia MI. Prevalence of pressure ulcers in hospitals in Brazil and association with nutritional status-a multicenter, cross-sectional study. Nutrition. 2013;29:646-9.

14. Cereda E, Klersy C, Rondanelli M, Caccialanza R. Energy balance in patients with pressure ulcers: a systematic review and meta-analysis of observational studies. J Am Diet Assoc. 2011;111:1868-76.

15. Donini LM, Poggiogalle E, Molfino A, Rosano A, Lenzi A, Rossi Fanelli F, et al. Mini-nutritional assessment, malnutrition universal screening tool, and nutrition risk screening tool for the nutritional evaluation of older nursing home residents. J Am Med Dir Assoc. 2016;17:959. e11-8.

16. Christner S, Ritt M, Volkert D, Wirth R, Sieber CC, Gassmann KG. Evaluation of the nutritional status of older hospitalised geriatric patients: a comparative analysis of a Mini Nutritional Assessment (MNA) version and the Nutritional Risk Screening (NRS 2002). J Hum Nutr Dietetics: Off J Br Dietetic Assoc. 2016;29:704-13.

17. Kondrup J, Rasmussen HH, Hamberg O, Stanga Z. Nutritional risk screening (NRS 2002): a new method based on an analysis of controlled clinical trials. Clin Nutr. 2003;22:321-36.

18. Seiler W, Stähelin H. Decubitus ulcers: treatment through five therapeutic principles. Geriatrics. 1985;40:30-44.

19. Cruse J, Lewis R, Roe D, Dilioglou S, Blaine M, Wallace W, et al. Facilitation of immune function, healing of pressure ulcers, and nutritional status in spinal cord injury patients. Exp Mol Pathol. 2000;68:38-54.

20. Zhou XJ, Vaziri ND, Segal JL, Winer RL, Eltorai I, Brunnemann SR. Effects of chronic spinal cord injury and pressure ulcer on 25 (OH)-vitamin D levels. J Am Paraplegia Soc. 1993;16:9-13.

21. van der Wielen H, Post MWM, Lay V, Glasche K, Scheel-Sailer A. Hospital-acquired pressure ulcers in spinal cord injured patients: time to occur, time until closure and risk factors. Spinal Cord. 2016;54:726-31.

22. DeVivo MJ, Biering-Sorensen F, New P, Chen Y. Standardization of data analysis and reporting of results from the International Spinal Cord Injury Core Data Set. Spinal Cord. 2011;49:596-9.

23. Post MWW, Brinkhof MW, von Elm EM, Boldt CM, Brach MM, Fekete CP, et al. Design of the Swiss Spinal Cord Injury Cohort Study. Am J Phys Med Rehabilitation. 2011;90:S5-16.
24. Jenkins MA, Brown DJ, Ierino FL, Ratnaike SI. Cystatin C for estimation of glomerular filtration rate in patients with spinal cord injury. Ann Clin Biochem. 2003;40:364-68.

25. Scivoletto G, Fuoco U, Morganti B, Cosentino E, Molinari M. Pressure sores and blood and serum dysmetabolism in spinal cord injury patients. Spinal Cord. 2004;42:473-6.

26. Gurcay E, Bal A, Gurcay AG, Cakci A. Evaluation of blood and serum markers in spinal cord injured patients with pressure sores. Saudi Med J. 2009;30:413-7.

27. Flueck JL, Perret C. Vitamin D deficiency in individuals with a spinal cord injury: a literature review. Spinal Cord. 2017;55:428-34.

28. Barbonetti A, Sperandio A, Micillo A, D'Andrea S, Pacca F, Felzani G, et al. Independent association of vitamin D with physical function in people with chronic spinal cord injury. Arch Phys Med Rehabil. 2016;97:726-32.

29. Oda Y, Tu C-L, Menendez A, Nguyen T, Bikle DD. Vitamin D and calcium regulation of epidermal wound healing. J Steroid Biochem Mol Biol. 2016;164:379-385.

30. Bischoff-Ferrari HA, Dawson-Hughes B, Orav EJ, Staehelin HB, Meyer OW, Theiler R, et al. Monthly high-dose vitamin $\mathrm{D}$ treatment for the prevention of functional decline: a randomized clinical trial. JAMA Int. Med. 2016;176:175-83.

31. Cereda E, Klersy C, Serioli M, Crespi A, D'Andrea F. A nutritional formula enriched with arginine, zinc, and antioxidants for the healing of pressure ulcers: a randomized trial. Ann Intern Med. 2015;162:167-74.

32. Sakae K, Yanagisawa H. Oral treatment of pressure ulcers with polaprezinc (zinc L-carnosine complex): 8-week open-label trial. Biol Trace Elem Res. 2014;158:280-88.

33. Kriz J, Schuck O, Horackova M. Hyponatremia in spinal cord injury patients: new insight into differentiating between the dilution and depletion forms. Spinal Cord. 2015;53: 291-96.

34. Raffoul W, Far MS, Cayeux M-C, Berger MM. Nutritional status and food intake in nine patients with chronic low-limb ulcers and pressure ulcers: importance of oral supplements. Nutrition. 2006;22:82-8.

35. Wong S, Derry F, Jamous A, Hirani SP, Grimble G, Forbes A. Validation of the spinal nutrition screening tool (SNST) in patients with spinal cord injuries (SCI): result from a multicentre study. Eur J Clin Nutr. 2012;66:382-7. 